\title{
Supporting Effects of Base Layers on the Lateral Pile Performance
}

\author{
Dr.-Ing. Jung Stefan ${ }^{1}$ \\ ${ }^{1}$ Dr. Jung + Lang Ingenieure GmbH \\ Europaallee 17, 66113 Saarbruecken, Germany \\ jung@JL-ingenieure.com
}

\section{Extended Abstract}

The horizontal pile performance is generally affected by nonlinear soil stiffness properties represented by the horizontal subgrade reaction modulus. In case of significant horizontal loads such as earthquakes e.g. piles will be strongly stressed by bending effects if they would be embedded in soft soils with low lateral stiffness. The horizontal deflection of pile heads caused by horizontal loads was investigated by field tests in deep soft marine sediments at the west coast of Mexico.

The pile tests were carried out on driven piles with squared section a $\mathrm{b}=0,5 \mathrm{~m} \times 0,5 \mathrm{~m}$. The piles were driven through the soft soil layer until the underlying hard clay at depth of $20 \mathrm{~m}$. At final depth no further penetration progress was obtained where a flexible vertical support could be assumed. The horizontal force was applied with a 50t load cell jacked up by the reaction pile (bored pile, diameter 1,0m). The load was applied in several load steps of about $30 \mathrm{kN}$ up to $150 \mathrm{kN}$, then fully unloaded and step by step reloaded until the maximum test load of $443 \mathrm{kN}$ was reached.

The tests were carried out on piles that were embedded in a thin layer of high compacted embankment. At a reference load step of $25 \mathrm{t}$ a horizontal pile head displacement of $25 \mathrm{~mm}$ and a pile head inclination of 0,5 degree were measured.

In order to evaluate the influence of the compacted embankment comparative tests followed on piles with an opened gap between pile shaft and embankment. With these tests the measured horizontal pile head displacement at the reference load step of $25 \mathrm{t}$ was up to 4 times higher and the pile head inclination was 3 times higher than for the piles in full contact with the embankment.

Parametric studies were done in order to investigate the influence of soft soil properties on the resulting pile displacements. It was found out that pile displacements are only slightly influenced by the horizontal subgrade modulus of soft subsoils and deeper soil layers. The results of recalculation were mainly related to the stiffness and compaction of the embankment.

Considering the known material properties of the embankment as well as of the subsoil conditions numerical calculations were carried out. The simulations confirmed the measured pile behavior of the tests. The numerical static calculations were based on the subgrade reaction method representing the soft soil conditions. The horizontal stresses were limited to the maximum possible earth resistance (theory of Coulomb) based on analytical earth pressure theory. The measured pile displacements and inclination could be simulated and confirmed for the reference load as well as for all other load steps.

The calculations showed that such compacted embankments with high stiffness are causing significant supporting effects on horizontal pile performance even the thickness of that stiff layer is less than $10 \%$ of pile length. Pile displacements and pile head inclination are mainly related to embankment qualities such as material, compaction and thickness. With these results an improved pile design was possible in order to realize a more economic foundation. Furthermore the results can be taken for future project with similar conditions. 